\title{
A EXPANSÃO DOS REFLORESTAMENTOS DE EUCALIPTO NO ESTADO DE GOIÁS
}

\author{
Humberto Angelo ${ }^{1}$, Felipe Ferreira Paulucio ${ }^{2}$, Alexandre Nascimento de Almeida ${ }^{3}$, \\ Eraldo Aparecido Trondoli Matricardi ${ }^{1}$, Philipe Ricardo Casemiro Soares ${ }^{4}$ \\ ${ }^{1}$ Universidade de Brasília, Departamento de Engenharia Florestal, Brasília, Distrito Federal, Brasil - humb@unb.br; \\ ematricardi@gmail.com \\ ${ }^{2}$ Universidade de Brasília, Curso de Engenharia Florestal, Brasília, Distrito Federal, Brasil - paulucio@ gmail.com \\ ${ }^{3}$ Universidade de Brasília, Faculdade UnB Planaltina, Planaltina, Distrito Federal, Brasil - alexalmeida@unb.br \\ ${ }^{4}$ Universidade do Estado de Santa Catarina, Departamento de Engenharia Florestal, Lages, Santa Catarina, Brasil - \\ a2pcs@cav.udesc.br \\ Recebido para publicação: 05/09/2013 - Aceito para publicação: 17/09/2014
}

\begin{abstract}
Resumo
O reflorestamento com eucalipto está em franca expansão no Brasil devido à demanda dessa matériaprima na indústria e construção civil. No entanto, apesar da importância das florestas plantadas como principal insumo para a indústria de base florestal e outros produtos, o eucalipto no estado de Goiás tem sido pouco estudado. Um dos motivos para a ausência de estudos no estado deve-se à falta de dados desagregados e à grande pulverização dos plantios, dificultando o levantamento dos mesmos. Este trabalho teve com objetivo levantar e analisar a evolução da área destinada ao plantio do eucalipto em três municípios do estado de Goiás. Como base metodológica, empregaram-se técnicas de análise de regressão e geoprocessamento com dados de sensoriamento remoto. Os resultados deste estudo indicam um forte potencial da atividade florestal não verticalizada nos municípios goianos de Alexânia, Abadiânia e Anápolis.
\end{abstract}

Palavras-chave: Goiás; plantações florestais; Eucalyptus spp.; geoprocessamento.

\begin{abstract}
Evolution of eucalyptus plantations in the Goiás State. Reforestation with eucalyptus is booming in Brazil due to the demand of this raw material in industry and construction. However, despite the importance of planted forests as the main raw material for the forest-based industry and other products, the eucalyptus in the Goias State has been little studied. One reason for the lack of studies in the Goias State is due to the lack of disaggregated data and large spray of eucalyptus plantations in the state, making it difficult to obtain forestry statistics. The objective is to collect and analyze the evolution of the area planted with eucalyptus in three municipalities from Goias state. The methodology is composed by regression analysis and geoprocessing with remote sensing data. The results of this study indicate a strong potential forest from private nonindustrial lands in the municipalities of Alexânia, Abadiânia Anápolis.

Keywords: Goias State; forest plantations; Eucalyptus spp.; geoprocessing.
\end{abstract}

\section{INTRODUÇÃO}

O setor florestal começou a galgar posições elevadas de importância para a economia nacional a partir da década de 1960. Nessa época, foi criada a política governamental de incentivos fiscais, com o objetivo de implantar florestas de rápido crescimento e diminuir a exploração dos recursos de florestas naturais (NOVAIS, 2006).

Um grupo de espécies que se destacou foi o gênero Eucalyptus, que, segundo Rapassi et al. (2008), possui mais de 600 espécies que se desenvolvem em condições diversas de solo e clima. A maioria delas atinge altura entre 30 e 50 metros, típicas de florestas altas, e de 10 a 25 metros, características de florestas abertas. E. grandis, E. saligna e E. urophylla são as principais espécies cultivadas em regiões de clima tropical (EMPRESA BRASILEIRA DE PESQUISA AGROPECUÁRIA (EMBRAPA), 2011). 
A eucaliptocultura, buscando suprir a demanda de madeira, teve grande impulso nos últimos 30 anos, em virtude da vasta rede experimental instalada por órgãos públicos e empresas particulares. A área destinada ao plantio de eucalipto no Brasil apresentou crescimento médio de 6,03\% ao ano entre 2006 e 2012, chegando a 5.102.030 ha de área plantada, sendo o estado de Goiás responsável por, aproximadamente, 38.081 ha desse total (ASSOCIAÇÃO BRASILEIRA DE PRODUTORES DE FLORESTAS PLANTADAS (ABRAF), 2013).

Goiás encontra-se, atualmente, na $11^{\underline{a}}$ posição em áreas de florestas plantadas no país (ABRAF, 2013), e a microrregião de Catalão é a primeira dentro do estado, porém com pequena quantidade de informação disponível. As plantações de eucalipto presentes nessa região destinam-se ao abastecimento de companhias mineradoras instaladas em Catalão, que utilizam a madeira como lenha para alimentar os fornos de secagem de minério (FIDELIS; LIMA, 2009).

Visando obter mais informações, é possível realizar levantamento e mapeamento do uso e ocupação da porção do espaço geográfico em estudos ambientais utilizando técnicas de sensoriamento remoto, juntamente com o geoprocessamento (RIBEIRO; MARACAJÁ, 2008). Recorrer a essa ferramenta evita que seja mantido contato direto com o objeto (ROSA, 1990).

Segundo Machado (2006), poucos são os estudos desenvolvidos para avaliação de área plantada por meio do sensoriamento remoto, sendo São Paulo o estado com maior número de informações de reflorestamento provenientes dessa fonte. $\mathrm{O}$ sensoriamento remoto, além de reduzir os custos do projeto e possibilitar o acesso a áreas acidentadas, permite agilidade na obtenção dos dados, pois requer visitas a campo apenas para validação.

Assim sendo, este trabalho aborda o reflorestamento com eucalipto no estado de Goiás. O objetivo é levantar e analisar a evolução da área plantada dessa espécie em três municípios do estado: Alexânia, Abadiânia e Anápolis, no período de 2003 a 2010.

\section{MATERIAL E MÉTODOS}

\section{Área de estudo}

Foram estudados os municípios de Alexânia, Abadiânia e Anápolis, os quais são localizados no estado de Goiás, com área total de 2.826,175 km² e altitude variando de 1.017 a 1.096 metros (Figura 1).

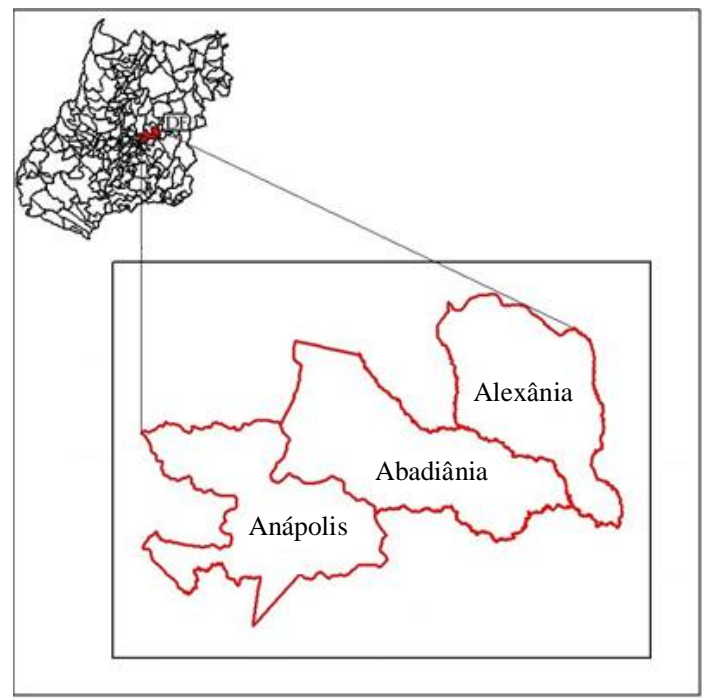

Figura 1. Localização da área de estudo.

Figure 1. Location of the study area.

Os municípios apresentam áreas semelhantes e próximas a 1 milhão de $\mathrm{km}^{2}$. Abadiânia é o maior, com $1.045 .026 \mathrm{~km}^{2}$, seguido de Anápolis e Alexânia, com áreas respectivas de $933.156 \mathrm{~km}^{2}$ e $847.893 \mathrm{~km}^{2}$. No entanto, Anápolis é o município mais populoso, com 334 mil habitantes. Já Abadiânia e Alexânia contam com apenas 24 e 16 mil habitantes, respectivamente (INSTITUTO BRASILEIRO DE GEOGRAFIA E ESTATÍSTICA (IBGE), 2010). 
Predomina na região o clima tropical de savana do tipo AW, conforme classificação de Köppen, ocorrendo chuvas concentradas no verão (outubro-abril) e estação seca no inverno (maio-setembro). A temperatura média da região gira em torno de $18^{\circ}$ a $26^{\circ} \mathrm{C}$. O índice pluviométrico ocorre entre os meses de setembro e abril, oscilando de 1.200 a $2.500 \mathrm{~mm}$, com chuvas mais concentradas no verão (INSTITUTO NACIONAL DE METEOROLOGIA (INMET), 2011).

\section{Quantificação anual da área reflorestada com eucalipto entre 2003 e 2010}

Empregaram-se 16 imagens de satélite obtidas junto ao Instituto Nacional de Pesquisas Espaciais (INPE), no período entre 2003 e 2010 (INPE, 2011), a fim de quantificar o crescimento da área destinada ao plantio de eucalipto em cada município.

Para a seleção das imagens que cobrem o estado de Goiás, recorreu-se à grade do satélite LANDSAT, analisando-se 16 imagens das órbitas/pontos 221/071 e 222/071 do satélite LANDSAT 5, sensor TM, bandas 3, 4 e 5, adquiridas no período de 2003 a 2010.

O georreferenciamento das imagens foi feito utilizando-se como base cartográfica os arquivos vetoriais em formato shapefile, contendo os rios e limites dos municípios do estado de Goiás (SIEG, 2011) no sistema de projeção UTM e Datum WGS 1984. O processamento das imagens e a montagem dos mosaicos foram feitos com os aplicativos computacionais ENVI 4.3® e Arcgis 9.3®.

As áreas de plantio de eucalipto foram identificadas e mapeadas visualmente na tela de computador, em escala 1:50.000. Para isso, foi utilizada a composição colorida RGB das bandas 4 (infravermelho próximo), 5 (infravermelho médio) e 3 (vermelho). A interpretação visual preliminar foi verificada em campo e, posteriormente, realizaram-se as correções e a interpretação final das áreas plantadas com eucalipto da área de estudo.

\section{Cálculo da taxa de crescimento anual composta}

A estimativa da taxa de crescimento anual composta da área plantada com eucalipto para os municípios em análise foi obtida conforme Gujarati (2000). De acordo com o autor, o processo de cálculo pode ser realizado da seguinte maneira: sejam $\mathrm{Y}_{0}$ e $\mathrm{Y}_{t}$, respectivamente, as áreas com plantios de eucalipto no período inicial e no instante $t$, pode-se aplicar a equação (1) para o cálculo da taxa de crescimento anual.

$$
Y_{t}=Y_{0}(1+r)^{T}
$$

em que: $r=$ taxa composta; $T=$ período.

Calculando o logaritmo natural, pode-se reescrever a equação (1) conforme (2):

$$
\ln Y_{t}=\ln Y_{0}+T \ln (1+r)
$$

Sendo $\beta_{1}=\ln Y_{0}$ e $\beta_{2}=\ln (1+r)$, e adicionando-se o termo de perturbação $\varepsilon_{t}$ na equação (2), obtêmse a equação (3):

$$
\ln Y_{t}=\beta_{1}+\beta_{2} T+\varepsilon_{t}
$$

Conforme o modelo (3), o coeficiente de inclinação $\left(\beta_{2}\right)$ mede a variação proporcional constante em $Y$ para uma dada variação absoluta no valor do regressor, neste caso, a variável $T$. A taxa de crescimento percentual em $Y$ no decurso do período de 2003 a 2010 é obtida pelo cálculo do antilog de $\beta_{2}$, com uma posterior subtração por 1 e, por fim, a multiplicação do resultado por 100.

\section{RESULTADOS E DISCUSSÃO}

A distribuição espacial dos plantios de eucalipto e a sua evolução temporal são apresentadas na figura 2 para o período de 2003 e 2010.

Dado à distribuição espacial pulverizada dos maciços, além da ausência de grandes empresas verticalizadas com a atividade florestal na região, pode-se caracterizar a produção florestal dos municípios, predominantemente, como de produtores rurais, os quais descobriram os plantios comerciais de eucalipto como uma oportunidade de negócio para atender a demanda da construção civil e a indústria consumidora de biomassa. 


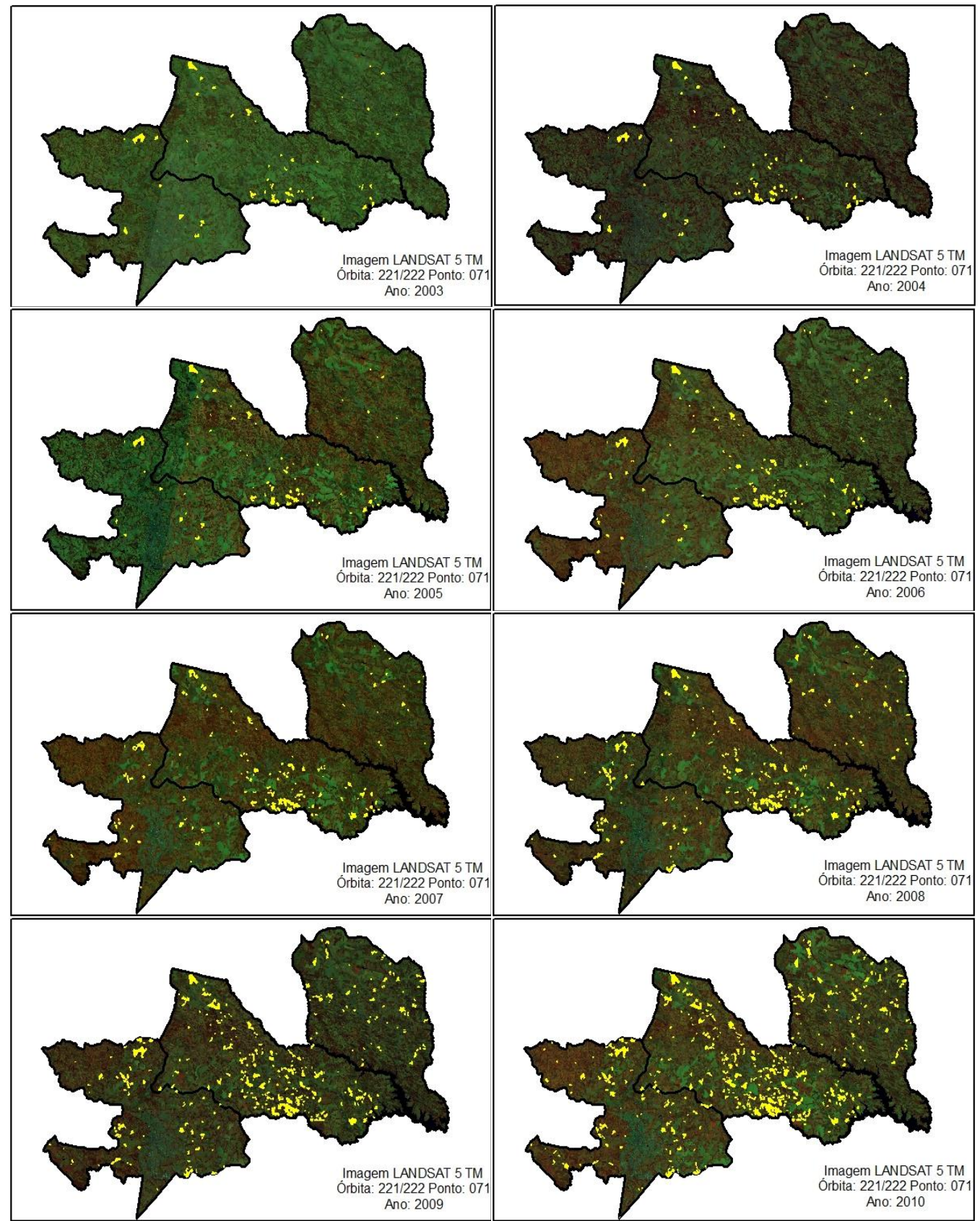

Figura 2. Evolução das áreas de plantios com eucalipto no período 2003-2010.

Figure 2. Evolution of eucalyptus plantations in the period 2003-2010.

A tabela 1 mostra a evolução da área ocupada com eucalipto nos municípios analisados, a taxa de crescimento da atividade e a participação do eucalipto na área total do município. Para efeito de comparação, incluíram-se os dados para o Brasil, Minas Gerais (estado brasileiro com maior área de eucalipto) e Goiás.

Machado (2006), ao aferir a área total destinada aos plantios de eucalipto no estado de Goiás em 2002, encontrou 6 e 379 hectares de área plantada com eucalipto nos municípios de Alexânia e Anápolis, respectivamente. Esses resultados são condizentes com os valores obtidos pelo presente estudo para o ano de 2003. 
Tabela 1. Evolução da área (ha) com eucalipto por município no período 2003-2010.

Table 1. Evolution of the area with eucalyptus by municipality during the period 2003-2010.

\begin{tabular}{|c|c|c|c|c|c|c|}
\hline Ano & Alexânia & Abadiânia & Anápolis & Brasil & Minas Gerais & Goiás \\
\hline $2003^{1}$ & 30,99 & 760,65 & 431,27 & - & - & - \\
\hline 2004 & 34,56 & 875,19 & 424,73 & 3.199 .816 & 1.040 .048 & 44.114 \\
\hline 2005 & 37,84 & 961,79 & 336,95 & 3.462 .719 & 1.119 .129 & 47.542 \\
\hline 2006 & 105,09 & $1.327,82$ & 416,30 & 3.745 .794 & 1.181 .429 & 49.637 \\
\hline 2007 & 152,43 & $1.607,39$ & 536,49 & 3.969 .711 & 1.218 .212 & 51.279 \\
\hline 2008 & 387,00 & $2.002,08$ & 880,29 & 4.325 .430 & 1.278 .210 & 56.880 \\
\hline 2009 & 857,58 & $3.389,32$ & $1.260,14$ & 4.515 .730 & 1.300 .000 & 57.940 \\
\hline 2010 & $1.242,82$ & $4.134,01$ & $1.666,63$ & 4.754 .334 & 1.400 .000 & 58.519 \\
\hline $\begin{array}{l}\text { Taxa de crescimento } \\
(\% \text { aa) }\end{array}$ & 79,68 & 28,40 & 23,99 & 6,93 & 4,60 & 5,02 \\
\hline $\begin{array}{l}\text { Porcentagem de } \\
\text { eucalipto na área da } \\
\text { região em } 2010\end{array}$ & 0,004 & 0,002 & 0,001 & 0,56 & 2,39 & 0,17 \\
\hline
\end{tabular}

Fonte: Dados da pesquisa e ABRAF (2010).

${ }^{1}$ Não disponível pela ABRAF (2010). Área de Alexânia, Abadiânia, Anápolis, Brasil, Minas Gerais e Goiás igual a 847.893, $933.156,1.045 .026,8.515 .767,586.528$ e $340.086 \mathrm{~km}^{2}$, respectivamente $\left(1 \mathrm{~km}^{2}=100 \mathrm{ha}\right)$.

Entre os municípios analisados, Abadiânia exibiu a maior área reflorestada ao longo dos oito anos, seguido por Anápolis e Alexânia. Porém Alexânia é o município onde a atividade mais cresceu, quase dobrando a área de eucalipto ano a ano, devido, naturalmente, a valores muito baixos, bem como as condições propícias para a atividade florestal comparativamente à agrícola.

As taxas de crescimento da atividade nos municípios estudados supera, de longe, a média nacional, de Minas Gerais e do próprio estado de Goiás, refletindo o grande desenvolvimento da atividade florestal não verticalizada com a indústria. Além disso, a baixa participação do eucalipto nas áreas totais dos municípios, comparativamente à média nacional e do próprio estado de Goiás, sugere que o crescimento registrado tem potencial de se manter pelos próximos anos.

\section{CONCLUSÕES}

- O município de Abadiânia possui a maior área com plantio de eucalipto, seguido por Anápolis e Alexânia. Embora o município de Alexânia ainda conte com a menor área com eucalipto, em se mantendo as atuais taxas de crescimento, a área com eucalipto no município será maior que a de Anápolis já em 2011 e superior à de Abadiânia em 2013.

- O forte crescimento nos plantios de eucalipto, bem como a baixa participação do mesmo nas áreas dos municípios analisados, sugere um futuro promissor para a atividade florestal na região central de Goiás.

- A distribuição espacial dos plantios de eucalipto nos municípios se caracteriza pela sua atomização e por uma produção não verticalizada dos produtores, refletindo o potencial da atividade florestal na geração de renda em pequenas e médias propriedades.

\section{REFERÊNCIAS}

ASSOCIAÇÃO BRASILEIRA DE PRODUTORES DE FLORESTAS PLANTADAS (ABRAF). Anuário estatístico da ABRAF 2010: ano base 2009. Brasília, 2010. 140 p.

. Anuário estatístico da ABRAF 2013: ano base 2012. Brasília, 2013. 148 p.

EMPRESA BRASILEIRA DE PESQUISA AGROPECUÁRIA (EMBRAPA). Disponível em: <http://sistemasdeproducao.cnptia.embrapa.br/FontesHTML/Eucalipto/CultivodoEucalipto/02_indicacao _de_especies.htm>. Acesso em: 18/07/2011.

FIDELIS, A. C.; LIMA, J. D. Impactos ambientais da silvicultura no bioma cerrado. V SIMPÓSIO NACIONAL DE GEOGRAFIA AGRÁRIA, 2009. 11 p. Disponível em: <http://www.uff.br/vsinga /trabalhos/Trabalhos\%20Completos/Alex\%20Camargo\%20Fidelis.pdf>. Acesso em: 26/07/2011.

FLORESTA, Curitiba, PR, v. 45, n. 2, p. 223 - 228, abr. / jun. 2015.

Angelo, H. de et al.

ISSN eletrônico 1982-4688 / ISSN impresso 0015-3826

227

DOI: $10.5380 /$ rf.v45i2.33301 
GUJARATI, D. N. Econometria básica. 3. ed. São Paulo: Makron Books, 2000. 846 p.

INSTITUTO BRASILEIRO DE GEOGRAFIA E ESTATÍSTICA (IBGE). Disponível em: <http://www. ibge.gov.br>. Acesso em: 18/07/2011.

INSTITUTO NACIONAL DE METEOROLOGIA (INMET). Disponível em: <http://www.inmet.gov.br>. Acesso em: 28/07/2011.

INSTITUTO NACIONAL DE PESQUISAS ESPACIAIS (INPE). Disponível em: < http://www.dgi.inpe. br/CDSR/>. Acesso em: 30/01/2011.

MACHADO, S. J. M. Avaliação de áreas reflorestadas no Estado de Goiás no ano de 2002 com uso de imagens de satélite. FIM, p. 53. Monografia (Engenharia Florestal) - Faculdades Integradas de Mineiros, 2006.

NOVAIS, L. F. Análise da colheita florestal mecanizada em povoamentos de Eucalyptus spp na região de Coronel Fabriciano, MG. 33 f. Monografia (Engenharia Florestal) - Universidade Federal Rural do Rio de Janeiro, Seropédica, 2006.

RAPASSI, R. M. A.; TARSiTANO, M. A. A.; PEREIRA, J. C. R.; ARAÚJO, C. A. M. Cultura do eucalipto na região de Suzanópolis, estado de São Paulo: Análise econômica. Inf. Econ., v. 38, p. 7-13, 2008.

RIBEIRO, G. N.; MARACAJÁ, V. P. B. Utilização de técnicas de sensoriamento remoto e geoprocessamento no estudo dos recursos naturais. Revista Verde, Mossoró, v. 3, n. 1, p. 22 - 41, 2008.

ROSA, R. A utilização de imagens TM/Landsat em levantamento de uso de solo. In: SIMPÓSIO BRASILEIRO DE SENSORIAMENTO REMOTO, 6., 1990, São José do Rio Preto. Anais do... São José do Rio Preto, 1990. p. 419 - 425.

SISTEMA ESTADUAL DE ESTATÍSTICA E DE INFORMAÇÕES GEOGRÁFICAS DE GOIÁS (SIEG). Disponível em: 〈http://www.sieg.go.gov.br〉. Acesso em 30/01/2011. 